Disclosure of Interest: None declared

DOI: 10.1136/annrheumdis-2017-eular.2961

\section{SAT0044 A 10-YEAR FOLLOW UP STUDY OF EARLY SERONEGATIVE ARTHRITIS DIAGNOSED AT AN ADULT AGE}

K. Paalanen, J. Asikainen, T. Rannio, P. Hannonen, T. Sokka. Rheumatology Department, KSSHP, JyväskyIÄ, Finland

Background: Up to $20-30 \%$ of patients enrolled into RA cohorts and clinical trials are seronegative. However, in studies examining predictors, prognosis, and response to treatment, seropositive and seronegative groups of patients seem to behave differently. Only a few studies have focused on the long term follow up of seronegative arthritis

Objectives: To investigate long-term outcomes of patients with seronegative arthritis during a 10-year follow-up period including clinical outcomes and reclassification of diagnosis when applicable.

Methods: A total of 1046 patients were classified as early RA in 1997-2005 at single rheumatology center and scheduled for a ten year follow-up, including 434 seronegative patients who are subjects of the present analysis. Follow-up examinations were carried out for at least 2 years and then at 5 and 10 years by the treating specialist including complete clinical examination and patient reported outcomes. In addition, case -reviews were performed, with re-classification of the cases when applicable

Results: Among the 434 seronegative patients $(69,4 \%$ women, mean age 58$)$, 271 subjects were seen for the 10 year visit with the mean disease activity DAS28 of 2,3 (SD 1,02) and the mean HAQ of 0,71 (SD 0,72 ). Out of the remaining 146 patients, 88 had died and 53 did not attend the 10 -year visit due to altered diagnosis, refusal or comorbidity. Five patients had dropped out and files of 17 patients were missing. During the follow-up of 10 years, $12 / 434(2,7 \%)$ patients could be classified as seropositive or erosive RA: 4 turned seropositive (2 for ACPA and 2 for RF [ $>2 x$ normal level]) and 8 developed erosions typical for RA. Reclassification revealed $70(16,1 \%)$ cases of polymyalgia rheumatica, $47(10,8 \%)$ cases of osteoarthrosis without evidence of inflammatory disease, $47(10,8 \%)$ cases of psoriatic arthritis, $39(9,0 \%)$ cases of spondylarthritis and $16(3,7 \%)$ cases of plausible reactive arthritis. Few cases were reclassified as gout $(11$ cases $(2,5 \%))$ and pseudogout $(3$ cases $(0,7 \%))$. Also paraneoplastic arthritis (6 cases $(1,4 \%)$ ), juvenile arthritis (5 cases $(1,2 \%))$, hemochromatosis (2 cases $(0,5 \%))$, ankylosing spondylitis (2 cases $(0,5 \%))$ and temporal arteritis $(2$ cases $(0,5 \%))$ were revealed during follow up. One case of each reflex sympathetic dystrophy, trauma-induced arthritis, meniscal injury, optional Nasu Hakola disease, microscopic polyangiitis (MPA), granulomatous polyangiitis (GPA), antisynthetase syndrome and colitis ulcerosa were also found. The remaining 147 patient $(33,8 \%)$ could not be reclassified in any clear cut diagnosis. A total of 44 of these undifferentiated cases had transient arthritis, 43 cases had features of seronegative spondylarthritis and 57 cases remained totally unspecified, while three patients had features of inflammatory connective tissue disease (SLE and Sjögren's syndrome), but they did not meet available classification criteria. In addition, files of $17(3,9 \%)$ patients were missing from the analyses.

Conclusions: Over a 10 -year period, $97 \%$ of seronegative patients remained seronegative and did not develop RA-like erosions. Reclassification revealed significant heterogeneity in the diagnosis of seronegative RA. Therefore, seronegative arthritis should not be studied as a homogenous disease entity.

References:

[1] Padyukov, Arthritis Rheum 2004, 50: 3085-3092.

[2] van Dongen, Arthritis Rheum 2007, 56: 1424-1432.

[3] Jantti, Clin Rheumatol 2002, 21: 353-356.

Disclosure of Interest: None declared

DOI: 10.1136/annrheumdis-2017-eular.2332

\section{SAT0045 11 YEARS' FOLLOW-UP OF A DANISH 2-YEAR TREAT-TO- TARGET RANDOMIZED CONTROLLED TRIAL IN PATIENTS WITH EARLY RHEUMATOID ARTHRITIS: BASELINE PREDICTORS OF FUNCTIONAL AND RADIOGRAPHIC OUTCOMES}

M.L. Hetland ${ }^{1,2}$, K. Stengaard-Petersen ${ }^{3}$, P. Junker ${ }^{4}$, H. Lindegaard ${ }^{4}$, ${ }_{\text {T. Ellingsen }}^{4}$, J. Pødenphant ${ }^{5}$, H. Skjødt ${ }^{6}$, A. Vestergaard ${ }^{7}$, B. Ejbjerg ${ }^{8}$, S. Jacobsen ${ }^{9}$, N.S. Krogh ${ }^{10}$, M. Østergaard ${ }^{2}$, K. Hørslev-Petersen ${ }^{11}$. ${ }^{1}$ DANBIO; ${ }^{2}$ COPECARE, Rigshospitalet, Glostrup; ${ }^{3}$ Department of Rheumatology, University Hospital, Aarhus; ${ }^{4}$ Department of Rheumatology, University Hospital, Odense; ${ }^{5}$ Department of Rheumatology, Gentofte Hospital, Gentofte;

${ }^{6}$ Department of Rheumatology, Rigshospitalet, Glostrup; ${ }^{7}$ Department of Radiology, Hvidovre Hospital, Hvidovre; ${ }^{8}$ Department of Rheumatology, Slagelse Hospital, Slagelse; ${ }^{9}$ Department of Rheumatology, Rigshospitalet; ${ }^{10}$ ZiteLab, Copenhagen; ${ }^{11}$ Kong Christian X's Gigthospital, Gråsten, Denmark

Background: Few RCTs have investigated long-term ( $>10$ years (yrs)) outcomes of goal-directed synovitis suppression in early rheumatoid arthritis (RA). The CIMESTRA trial was a 2-year double-blinded Danish multicenter study on aggressive treatment with csDMARDS (methotrexate (MTX) versus MTX and cyclosporine) in combination with intra-articular glucocorticoids $(1+2)$. Disease

\begin{tabular}{l|l|ll} 
Baseline predictors of: & & & \\
\hline -Functional status (HAQ10-)* & Coefficient & $\mathbf{9 5 \%} \mathbf{C I}$ & p-value \\
\hline DAS28 (per unit increase) & 0.10 & $0.02-0.18$ & 0.02 \\
\hline Anti CCP (positive) & 0.24 & $0.02-0.46$ & 0.03 \\
\hline -Radiographic progression ( $\triangle \mathrm{TSS}_{0-10-)^{*}}$ & Coefficient & $95 \% \mathrm{CI}$ & p-value \\
\hline Anti CCP (positive) & 7.69 & $0.91 ; 14.47$ & 0.03 \\
\hline MRI bone marrow edema (per unit increase) & 0.87 & $0.19 ; 1.55$ & 0.01 \\
\hline
\end{tabular}

": Initial baseline variables in the $\mathrm{HAQ} 1-(\$)$ and $\triangle \mathrm{TSS}$ :-10-(\#) multivariable linear models before backward selection
were: Total Sharp-van der Heijde-Score (TSS) $)^{i \varepsilon}$; Health Assessment Questionnaire scorel; Disease Activity Score (28.

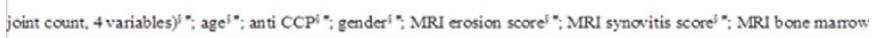
edema ${ }^{1 *}$. CI, confidence interval, $\mathrm{CCP}$, cyclic citrullinated peptide (dichotomized value), $\mathrm{MRI}$, magnetic resonance

imaging

control after 2 yrs was excellent with $\approx 50 \%$ in remission and halted radiographic progression in both groups. We present $11 \mathrm{yr}$ follow-up data.

Objectives: The aims were to 1) investigate the clinical and radiographic status and 2) identify baseline predictors of functional status and erosive progression. Methods: Of 160 patients (pts) included, 130 pts also had MRI of the wrist performed at baseline. 17 pts had died since baseline. All living pts were contacted and 120 signed informed consent to participate in a 11 yrs' follow-up visit assessing e.g. treatment, disease activity (DAS28, CRP, 4 variables), physical function (HAQ), X-ray of hands and feet. Baseline MRI was scored by OMERACT rheumatoid arthritis MRI scoring (RAMRIS) system, X-rays by Sharp-van der Heijde total Sharp Score (TSS). Multivariable linear regression analyses of a panel of baseline variables (see foot note in table) with backward selection were performed with $\mathrm{HAQ}$ at $11 \mathrm{yrs}\left(\mathrm{HAQ}_{11}\right)$ and radiographic progression since baseline $\left(\triangle T \mathrm{TSS}_{0-11}\right)$ as dependent variables.

Results: 120 of 160 pts $(75 \%)$ completed the 11 yrs visit. 96 pts with available baseline MRI and X-rays of both time points were included in the prediction models. Withdrawal analysis comparing the 160 pts with the 40 and 64 pts who were not included showed similar baseline characteristics except for higher DAS28 and HAQ score for withdrawers. Follow-up was after 11.6 yrs (10.7-12.2) (median (IQR)). Pts were 63 yrs (55-72) and $70 \%$ females. $20 \%$ received biologics (+/csDMARD), 53\% csDMARD alone, $27 \%$ were in drug free remission. DAS28 was 2.0 (1.5-2.6); pain score: $1 \mathrm{~cm}(0.3-3)$; pt. global: $1.1 \mathrm{~cm}(0.2-2.9)$; swollen joint count (28SJC): 0 (0-0); tender joint count (28TJC): $0(0-1) .76 \%$ of pts were in DAS28 remission; HAQ-score was $0.25(0-0.75) ; \Delta \mathrm{TSS}_{0-11}$ (median (IQR)):4 $(0-13) ; \triangle T_{S S}{ }_{0-11}($ mean $\left.\pm S D): 10.9 \pm 16.9\right)$. The annual progression rate since baseline was median (IQR):0.4 (0-1.1); mean \pm SD:0.96 \pm 1.52 . Multivariable linear regression analyses are shown in Table.

Conclusions: 11 years after diagnosis $75 \%$ were in DAS28 remission. HAQscore was low, and mean radiographic progression was $<1$ TSS unit/year. High DAS28 and positive anti-CCP at baseline were independent predictors of poorer functional status. Baseline MRI bone marrow edema and anti-CCP positivity were independent predictors of radiographic progression.

References:

[1] Arthritis Rheum 2006; 54: 1401-9.

[2] Ann Rheum Dis 2008; 67: 815-22.

Disclosure of Interest: M. L. Hetland Grant/research support from: AbbVie, BMS, MSD, Pfizer, Orion, Novartis, Biogen, Eli Lilly, K. Stengaard-Petersen: None declared, P. Junker: None declared, H. Lindegaard: None declared, T. Ellingsen: None declared, J. Pødenphant: None declared, H. Skjødt: None declared, A. Vestergaard: None declared, B. Ejbjerg: None declared, S. Jacobsen: None declared, N. S. Krogh: None declared, M. Østergaard Grant/research support from: Abbvie, BMS, Boehringer-Ingelheim, Celgene, Eli-Lilly, Centocor, GSK, Hospira, Janssen, Merck, Mundipharma, Novartis, Novo, Orion, Pfizer, Regeneron, Schering-Plough, Roche, Takeda, UCB, K. Hørslev-Petersen: None declared

DOI: 10.1136/annrheumdis-2017-eular.1720

\section{SAT0046 TNF ANTAGONIST DRUG SAFETY ASSESSMENT BY PHARMACOVIGILANCE SIGNALING AND POST-MARKETING ADVERSE EVENT REPORTS}

M. Cavaco ${ }^{1}$, F. Araujo ${ }^{2,3}$, J. Eurico Fonseca ${ }^{4,5}$, J. Goncalves ${ }^{1} .{ }^{1}$ iMed Research Institute of Medicines, Faculdade de Farmacia Universidade de Lisboa, Lisboa; ${ }^{2}$ Rheumatology Unit, Hospital de Sant'Ana, Cascais; ${ }^{3}$ Institute of Microbiology; ${ }^{4}$ Instituto de Medicina Molecular, Faculdade de Medicina da Universidade de Lisboa, Lisbon; ${ }^{5}$ Rheumatology Department, Centro Hospitalar de Lisboa Norte, EPE, Hospital de Santa Maria, Lisbon Academic Medical Centre, Lisboa, Portugal

Background: TNF antagonists have been equally effective in the treatment of immunoinflammatory diseases. However, differences in their characteristics and the introduction of biosimilars may be associated with different safety profiles. Objectives: The main goal of this study is to compare the safety of infliximab (IFX), etanercept (ETN), and adalimumab (ADA), as well as of IFX-biosimilar. Methods: We assessed the adverse events reported in the EudraVigilance database between 2004 and 2016. The MEdDRA ${ }^{\circledR}$ system was used to classify the adverse events according to the primary system organ class. For a direct 